\title{
PECTINA EXTRAÍDA DE CASCA DE PEQUI E APLICAÇÃO EM GELEIA LIGHT DE MANGA ${ }^{1}$
}

\author{
BEATRIZ DOS SANTOS SIQUEIRA², LETÍCIA DIAS ALVES 3 , \\ POLLYANNA NOVATO VASCONCELOS ${ }^{4}$, CLARISSA DAMIANI ${ }^{5}$, \\ MANOEL SOARES SOARES JÚNIOR ${ }^{6}$
}

RESUMO - Dentre os frutos do Cerrado, destaca-se o pequi (Caryocar brasiliense Camb.), que é constituído por aproximadamente $80 \%$ de casca, que é desprezada; no entanto, apresenta potencial de utilização em várias aplicações. O objetivo deste trabalho foi avaliar a influência das variáveis concentração de ácido cítrico, temperatura e tempo de extração sobre o rendimento e o grau de esterificação da pectina extraída da casca de pequi e compará-la com a pectina cítrica comercial aplicada na formulação de geleia light. Obtiveram-se rendimentos de pectina entre 14,89 e 55,86 g. $100 \mathrm{~g}^{-1}$. A pectina obtida da casca de pequi caracterizou-se por apresentar baixo grau de esterificação $(11,79-48,87 \%)$. A geleia light elaborada a partir da pectina da casca de pequi, extraída à temperatura de $84^{\circ} \mathrm{C}$ por 92 minutos, na presença de $2 \%$ de ácido cítrico, obteve boa aceitação por parte dos provadores, alcançando escores médios acima de 7,0, diferindo da geleia produzida com pectina cítrica comercial apenas na aparência. Conclui-se que é viável utilizar a pectina da casca de pequi como ingrediente para formulação de geleia light de manga.

Termos para indexação: Caryocar brasiliense Camb.; resíduo; análise sensorial.

\section{EXTRACTED PECTIN OF 'PEQUI' PEEL AND APPLICATION IN LIGHT MANGO JAM}

\begin{abstract}
Among the fruits of the Cerrado stands 'Pequi'(Caryocar brasiliense Camb.), which consists of approximately $80 \%$ of peel, but is ignored, however has potential for use in various applications. The objective of this study was to evaluate the influence of variables citric acid concentration, temperature and extraction time on yield and esterification degree of pectin extracted from the pequi peel, and compares it with commercial citrus pectin applied in the light formulation jam. It was obtained yields of pectin from 14.89 and $55.86 \mathrm{~g} .100 \mathrm{~g}^{-1}$. Pectin derived from peel pequi was characterized by having a low esterification degree (11.79 to $48.07 \%)$. The light jam made from the pectin extracted from the "pequi" peel at the temperature of $84{ }^{\circ} \mathrm{C}$ for 92 minutes in the presence of $2 \%$ citric acid, obtained good acceptance by the tasters, reaching mean scores above 7.0, differing from jam produced with commercial citrus pectin in appearance only. It follows that it is possible to use the pectin from pequi peel as an ingredient for formulation of mango light jam. Index terms: Caryocar brasiliense Camb., residue; sensory analysis.
\end{abstract}

\section{INTRODUÇÃO}

Dentre as frutíferas nativas do cerrado, destaca-se o pequizeiro (Caryocar brasiliense Camb.), cujo fruto é amplamente utilizado na culinária brasileira. No entanto, a casca do pequi, formada pelo epicarpo e mesocarpo externo e compreendendo aproximadamente $80 \%$ do peso total do fruto (VERA et al., 2005), geralmente é descarta. A farinha do mesocarpo externo do pequi (casca) é muito rica em fibra alimentar total, além de possuir carboidratos, cinzas, magnésio, cálcio, manganês e cobre. Entretanto, mais pesquisas são necessárias para caracterizar a farinha do mesocarpo externo do pequi, assim como para conferir o desempenho deste produto como ingrediente ou como matéria-prima (SOARES JÚNIOR et al., 2010).

Juntamente com as fibras insolúveis e demais solúveis, a pectina faz parte de um grupo complexo de polissacarídeos estruturais que são en-

\footnotetext{
1(Trabalho 043-12). Recebido em: 04-01-2012. Aceito para publicação em: 30-05-2012.

${ }^{2}$ Mestranda em Ciência e Tecnologia de Alimentos da Universidade Federal. Bolsista Capes DS. E-mail: beatrizsiqueira7@hotmail.com ${ }^{3}$ Engenheira de Alimentos da Universidade Federal de Goiás. E-mail: leticiadiasalves@gmail.com ${ }^{4}$ Engenheira de Alimentos da Universidade Federal de Goiás. E-mail: pollyvasconcelos@ @hotmail.com

${ }^{5}$ Doutor em Ciência e Tecnologia de Alimentos, Professor Adjunto I Escola de Agronomia e Engenharia de Alimentos da Universidade Federal de Goiás. E-mail: damiani@hotmail.com

${ }^{6}$ Doutor em Ciência e Tecnologia de Alimentos, Professor Associado I Escola de Agronomia e Engenharia de Alimentos da Universidade Federal de Goiás. E-mail mssoaresjr@hotmail.com
} 
contrados na parede celular primária e nas camadas intercelulares de plantas terrestres (MILOS et al., 2007). As substâncias pécticas, presentes na maioria das frutas e vegetais, mas em maior proporção no albedo das frutas cítricas e no bagaço de maçã, podem ser extraídas por diferentes métodos, com ácidos, álcalis ou enzimas (FERTONANI, 2006).

A extração de pectina é um processo de múltiplos estágios físicos e químicos em que a hidrólise, a extração de macromoléculas do tecido vegetal e sua solubilização sofrem influência de diversos fatores, como temperatura, $\mathrm{pH}$, tipo de ácido e tempo de extração (PAGÁN, 2001). A aplicação de pectina na indústria de alimentos é muito versátil, uma vez que este aditivo apresenta propriedades geleificantes, espessantes e estabilizantes, podendo ser utilizada em uma ampla variedade de produtos lácteos, cárneos, de panificação, geleias, bebidas, entre outros (MUNHOZ, 2008). A pectina vem sendo empregada na alimentação, visando a produzir efeitos fisiológicos benéficos ao organismo humano, tais como redução dos níveis de colesterol, de lipoproteínas, de ácidos biliares e de glicose.

O objetivo deste trabalho foi avaliar a influência da concentração de ácido cítrico, da temperatura e do tempo de extração sobre o rendimento e o grau de esterificação da pectina extraída a partir da farinha do mesocarpo externo de pequi, além de compará-la com a pectina cítrica comercial aplicada na produção de geleia light.

\section{MATERIAL E MÉTODOS}

A matéria-prima objeto de investigação deste trabalho foi o pequi (Caryocar brasiliense Camb.). Os frutos, oriundos de Mambaí, Goiás, Brasil, da safra de 2008, foram adquiridos em Goiânia, na Central de Abastecimento S/A de Goiás - CEASA-GO.

Para a obtenção da farinha de casca de pequi, os frutos foram lavados e selecionados considerando-se ausência de injúrias visuais e infecções, bem como uniformidade de tamanho, cor e firmeza. Em seguida, realizou-se o descascamento químico (remoção do epicarpo) em bateladas de aproximadamente 1 $\mathrm{kg}$, através da imersão em $10 \mathrm{~L}$ de solução de $\mathrm{NaOH}$ $\left(50,1 \mathrm{~g} \mathrm{~L}^{-1}\right)$, a $97{ }^{\circ} \mathrm{C}$, durante 7,05 minutos. Na sequência, os frutos foram lavados em água corrente para a remoção da cutícula queimada pela lixívia, com subsequente imersão em solução diluída (3\%) de ácido acético por 3 minutos, para a neutralização da alcalinidade residual. Após o corte, as cascas foram separadas dos pirênios, sendo submetidas ao branqueamento em água fervente, por 6 minutos, e desidratadas em estufa, por $16 \mathrm{~h}$, à temperatura de 60
${ }^{\circ} \mathrm{C}$. O produto desidratado, após resfriamento, foi moído e armazenado em sacos de polietileno sob abrigo da luz, conforme procedimentos recomendados por Soares Júnior et al. (2009).

Utilizou-se delineamento composto central rotacional com oito pontos fatoriais $\left(2^{3}\right)$, seis pontos axiais e seis repetições no ponto central, totalizando vinte ensaios. As variáveis independentes escolhidas foram o tempo de extração (minutos), a temperatura $\left({ }^{\circ} \mathrm{C}\right)$ e a concentração de ácido cítrico $(\% \mathrm{~m} / \mathrm{v})$. Os níveis originais reais das variáveis independentes estão apresentados juntamente com os níveis codificados na Tabela 1. O rendimento em massa e o grau de esterificação da pectina, em cada experimento, foram considerados variáveis resposta ou dependentes. Os ensaios foram conduzidos de forma aleatória. A pectina foi extraída em meio ácido, utilizando-se de ácido cítrico (MUNHOZ et al., 2010). Amostra de 4 $\mathrm{g}$ de farinha de casca de pequi foi dissolvida em 200 $\mathrm{mL}$ de solução de ácido cítrico com concentração variável. As extrações foram realizadas em diferentes condições experimentais de tempo (60-80 minutos), temperatura $\left(68-98^{\circ} \mathrm{C}\right)$ e concentração de ácido cítrico (1-9\%). Após extração ácida, a amostra foi resfriada a $4{ }^{\circ} \mathrm{C}$, por $2 \mathrm{~h}$, filtrada em tecido de náilon de serigrafia, e descartado o sobrenadante. Ao filtrado, contendo pectina, adicionou-se álcool etílico (95\%) na proporção 1:2 (uma parte de solução de pectina e duas partes de álcool). Após $1 \mathrm{~h}$ de repouso, houve precipitação da pectina, sendo esta separada por filtração. O gel obtido foi seco em estufa de secagem a $55^{\circ} \mathrm{C}$ até peso constante. $\mathrm{O}$ rendimento de pectina foi obtido segundo a equação 1 .

Rendimento $(\%)=\frac{\text { massa pectina extraida }(g) \times 100}{\text { massa de farinha em base seca }(g)} \quad(E q 1)$

As amostras de pectina obtidas nas condições experimentais foram quantificadas por titulometria, conforme descrito por Munhoz et al. (2010). As amostras de pectina obtidas nas condições experimentais ótimas foram quantificadas por titulometria. Aproximadamente $250 \mathrm{mg}$ de pectina foram umedecidos com $2 \mathrm{~mL}$ de álcool etílico P.A. e solubilizados em $25 \mathrm{~mL}$ de água deionizada sob agitação constante, por $30 \mathrm{~min}$, em agitador magnético, sendo em seguida determinado o $\mathrm{pH}$ da solução. As carboxilas livres dos ácidos anidrogalacturônicos foram neutralizadas com solução de $\mathrm{NaOH} 0,1 \mathrm{~N}$. As carboxilas esterificadas após saponificação com $10 \mathrm{~mL}$ de solução de $\mathrm{NaOH} 0,25 \mathrm{~N}$, por $30 \mathrm{~min}$, à temperatura ambiente, foram neutralizadas com 10 $\mathrm{mL}$ de solução de $\mathrm{HCl} 0,25 \mathrm{~N}$ e novamente neutralizadas com solução de $\mathrm{NaOH} 0,1 \mathrm{~N}$, obtendo-se então os valores de $\mathrm{mEq}$ de $\mathrm{NaOH}$ referentes 
aos dois tipos de carboxilas, livres e esterificadas, respectivamente, representados por $\mathrm{mEq}$ ' e $\mathrm{mEq}$ ". Com os dados obtidos, foram realizados os cálculos para a determinação da quantidade de mEq' e mEq" (Equação 2) e o grau de esterificação (Equação 3).

$\mathrm{mEq}_{1}{ }^{\prime}=\mathrm{N}_{1} \times \mathrm{V}_{1}$ e $\mathrm{mEq}{ }^{\prime}=\mathrm{N}_{2} \times \mathrm{V}_{2} \quad$ (Eq. 2)

Em que,

$m E q=m E q u i v a l e n t e ;$

$\mathrm{N}_{\mathrm{i}}=$ normalidade da solução $(N)$;

$\mathrm{V}_{\mathrm{i}}=$ volume $(L)$.

$G E=\frac{m E q^{\prime}}{m E q^{\prime}+m E q^{\prime}}$

Em que,

$\mathrm{GE}=$ Grau de esterificação.

Os dados de rendimento e do grau de esterificação das pectinas obtidas foram submetidos à análise de variância e regressão múltipla, utilizando-se das variáveis codificadas.

Após a determinação do rendimento e do grau de esterificação da pectina extraída, procedeu-se à avaliação da sua qualidade tecnológica por meio da elaboração de geleia light. Para isto, mangas da cv. Tommy foram descascadas manualmente, trituradas em liquidificador, e a polpa, peneirada. Mediram-se o $\mathrm{pH}$ e o ${ }^{\circ} \mathrm{Brix}$ da polpa, para garantir que estes estivessem dentro do valor desejado (aproximadamente 3,5 e $20^{\circ}$ Brix, respectivamente). Para a elaboração das geleias light, foram adicionados $0,1 \%$ de edulcorante sucralose e $1 / 3$ do açúcar à polpa e levou-se a mistura para cocção. Posteriormente, adicionaram-se mais $1 / 3$ do açúcar, $0,5 \%$ de pectina cítrica comercial ou pectina de casca de pequi de baixa esterificação e $0,11 \%$ de cloreto de sódio. Depois de a mistura atingir $40^{\circ}$ Brix, adicionaram-se mais $1 / 3$ de açúcar (perfazendo $26,5 \%$ ) e $0,7 \%$ de ácido cítrico. Procedeu-se à concentração até o teor de sólidos solúveis desejados $\left(49^{\circ}\right.$ Brix $)$, conforme recomendado por Nachtigall et al. (2004).

Para a análise sensorial, utilizou-se do delineamento em blocos completos casualizados. Cada tratamento foi avaliado por cinquenta provadores não treinados. O método utilizado foi o de aceitabilidade, no qual se avaliaram a aparência, textura, sabor e aroma, utilizando escala hedônica estruturada (MEILGARD et al., 1988). Também foram obtidas informações sobre preferência entre as geleias, além da intenção de compra pelos provadores. Para comparação das médias obtidas na análise sensorial, foi empregado o teste de Tukey, ao nível de 5\% de probabilidade.

\section{RESULTADOS E DISCUSSÃO}

Os rendimentos médios de pectina extraída a partir da casca de pequi (Tabela 1) variaram entre 14,89 e 55,86 g. $100 \mathrm{~g}^{-1}$. Por meio da análise de variância (Tabela 2a), verificou-se que os efeitos lineares das variáveis temperatura e concentração de ácido cítrico e interação tempo (L) vs temperatura (L) foram significativos para o rendimento de pectina, quando os dados foram transformados. O efeito quadrático da temperatura $(\mathrm{Q})$ não foi significativo $(\mathrm{P}=0,11)$, mas foi mantido no modelo ajustado, por ser expressivo em relação à resposta. Portanto, as três variáveis afetaram a resposta. O modelo completo para rendimento transformado foi significativo $(\mathrm{P}=0,00000)$, com coeficiente de determinação $\left(\mathrm{R}^{2}\right)$ de 0,79155 . O modelo ajustado apresentou $\mathrm{R}^{2}$ de 0,73596, o que demonstra que $73,6 \%$ da variação da resposta são explicados pelo modelo. A Equação 4 apresenta o modelo ajustado construído para o rendimento transformado de pectina $\left(R_{\text {Transf }}\right)$ : temperatura (T), temperatura quadrática $\left(\mathrm{T}^{2}\right)$, concentração de ácido cítrico (Ac), interação tempo vs temperatura (t.T), todos em valores codificados.

$R_{\text {Transf. }}=0,34-0,03 * T+0,06 * A c-0,02 * T^{2}-0,03 * t * T$

(Eq.4)

O fator tempo apresentou efeito significativo $(\mathrm{P}<0,05)$ somente na forma de interação, portanto optou-se pela elaboração do gráfico temperatura vs concentração de ácido cítrico (Figura 1a), fixando-se o tempo no ponto central (120 minutos). Constatouse que o rendimento aumentou com a elevação da concentração de ácido cítrico. Ao se fixar a temperatura na faixa de $98^{\circ} \mathrm{C}$ e aumentar a concentração de ácido cítrico, o rendimento aumentou, enquanto ao se fixar a concentração de ácido em $1 \%$ e aumentar a temperatura de extração, o rendimento aumentou e diminui novamente (efeito quadrático). Quando se fixou a concentração de ácido cítrico na faixa de $9 \%$ e diminuiu-se a temperatura, o rendimento aumentou. Nas concentrações de ácido cítrico entre 8-9\%, os experimentos 6; 7 e 14promoveram maiores rendimentos de extração de pectina.

Conforme Fertonani (2006), a extração de pectina com ácido cítrico apresenta um rendimento crescente à medida que se aumenta a concentração de ácido. Este comportamento pode corresponder a uma extração de pectina semelhante àquela que ocorre na presença de ácidos minerais, mas com a incorporação de grupamentos ácidos esterificando as 
hidroxilas do carbono da posição 2 ou da posição 3 do ácido poligalacturônico ou as hidroxilas livres dos açúcares neutros acompanhantes.

A temperatura do processo de extração também influenciou no rendimento da extração de pectina da casca do pequi. Pagán e colaboradores (2001) obtiveram pectina do resíduo de pêssego estocado sob refrigeração. A operação unitária utilizou ácido nítrico em reator encamisado a 60 e $80^{\circ} \mathrm{C}$ e $\mathrm{pH}$ variando entre 1,20 e 2,53, durante 80 minutos. Os autores constataram que o $\mathrm{pH}$ e a temperatura influenciaram notavelmente sobre o rendimento da extração da pectina deste resíduo. Para tempo constante, com aumento da temperatura e diminuição do $\mathrm{pH}$, o rendimento de pectina aumentou, com maior rendimento de pectina a $80^{\circ} \mathrm{C}$, obtendo-se valores de $\mathrm{pH}$ menores que 1,50, em 60 minutos de extração.

As pectinas da casca do pequi apresentaram baixa esterificação, variando entre 11,79 e 48,07\%. Por meio da análise de variância (Tabela 2b), constatou-se que os efeitos lineares e quadráticos da variável concentração de ácido cítrico foram significativos $(\mathrm{P}<0,05)$ para o grau de esterificação. $\mathrm{A}$ interação temperatura $v s$ concentração de ácido cítrico não foi significativa $(\mathrm{P}=0,07)$, mas assim como a temperatura linear $(\mathrm{P}=0,21)$, contribuiu para melhorar o coeficiente de determinação ajustado do modelo. Portanto, a temperatura (L) e a interação entre temperatura e concentração de ácido cítrico foram mantidas no modelo ajustado.

O modelo completo foi significativo $(\mathrm{P}=0,00012)$, com $\mathrm{R}^{2}$ de 0,80474 , e o modelo ajustado apresentou $\mathrm{R}^{2}$ de 0,75268 . A Equação 5 apresenta o modelo ajustado construído para o grau de esterificação $(G E)$ das pectinas extraídas da casca de pequi. O modelo com os valores codificados foi ajustado, eliminando-se os fatores não significativos, com exceção dos termos anteriormente mencionados.

$G E=17,45+2,45 * T-10,10 * A c+4,59 * A c^{2}-4,71 * T^{*} A c$

O fator tempo não apresentou efeito significativo $(P>0,05)$ sobre o grau de esterificação das pectinas extraídas, portanto elaborou-se o gráfico temperatura vs concentração de ácido cítrico (Figura $2 b$ ), fixando-se o tempo no ponto central (120 minutos). Percebeu-se que o GE aumentou com a elevação da temperatura de extração e diminuiu com a concentração de ácido cítrico. Ao se fixar a temperatura na faixa de $98^{\circ} \mathrm{C}$ e diminuir a concentração de ácido cítrico, o grau de esterificação aumentou. $\mathrm{O}$ mesmo ocorreu ao se fixar a concentração de ácido em $1 \%$ e aumentar a temperatura de extração. $\mathrm{O}$ aumento do GE indicou que a concentração de ácido cítrico e a temperatura foram críticas nesse processo.

Condições severas de extração não somente aumentaram o rendimento, mas também a degradação dos polímeros. Dessa forma, as condições de maior desejabilidade de extração devem direcionar o equilíbrio das reações positivas, que liberam os polímeros solúveis em ácido, com as reações negativas, que hidrolisam as ligações glicosídicas e ésteres. Com a hidrólise ácida, que degrada a protopectina, ocorreram simultaneamente várias reações, isso induz a aceitar que as pectinas estão sendo hidrolisadas (HWANG, 1993), em especial as ligações éster existentes em grupamentos carboxílicos de resíduos de ácidos anidrogalacturônicos, o que pode ser observado nos experimentos 3; 4 e 13, que obtiveram menores rendimentos de extração (abaixo de 16\%) e apresentaram os maiores graus de esterificação (acima de 36\%).

A extração com concentração de ácido cítrico de $2 \%$ e a temperatura de $92{ }^{\circ} \mathrm{C}$, experimentos 3 e 4 , produziram pectinas com maiores graus de esterificação e rendimentos menores $(15,91 \%$ e $15,70 \%)$. Elevado efeito negativo da concentração do ácido sobre o grau de esterificação é visível, como esperado, pois as condições favorecem a reação de degradação da pectina com possível desesterificação, que transforma pectina com alto grau de metilação em pectina com baixo grau de metilação (CONSTENLA; LOZANO, 2003).

Marcon et al. (2005) obtiveram resultados semelhantes $(14,3 \%$ a $29,4 \%)$ aos encontrados neste trabalho para extração de pectina de bagaço de maçã com ácido cítrico a 5\%, tempos de extração entre 30-80 minutos e temperaturas entre $50-100{ }^{\circ} \mathrm{C}$. As pectinas obtidas a partir da casca de pequi, neste trabalho, apresentaram grau de esterificação inferior a $50 \%$, sendo, portanto, caracterizadas como pectinas de baixo teor de esterificação, podendo formar géis estáveis na ausência de açúcar, porém requerem a presença de íons bivalentes.

A geleia light elaborada a partir da pectina da casca de pequi, extraída na temperatura de $84^{\circ} \mathrm{C}$, com $2 \%$ de ácido cítrico e 92 minutos de extração, obteve boa aceitação por parte dos provadores, alcançando escores médios acima de sete e abaixo de oito (entre gostei regulamente e gostei muito) para os atributos aparência, textura, sabor e aroma, diferindo da geleia produzida com pectina cítrica comercial apenas na aparência (Tabela 3). A geleia light elaborada com pectina cítrica comercial foi mais aceita em relação à aparência, fato que pode ser justificado por a geleia elaborada com pectina de casca de pequi ter apresentado pontos pretos e coloração mais escura. A geleia light elaborada com pectina da casca de pequi apre- 
sentou textura menos firme, embora também tenha apresentado uma boa formação do gel, assim como a da pectina comercial cítrica. Esta textura menos firme, provavelmente, pode ser justificada pelo fato de a pectina não ter sido completamente dissolvida (pontos pretos). Os escores de sabor para a geleia elaborada com a pectina comercial cítrica foi apenas $2,7 \%$ maior que o da pectina extraída da casca de pequi. A pectina foi o único ingrediente que variou de uma formulação para outra, e esta não interferiu no aroma do produto, obtendo os escores entre gostei moderadamente (7) e gostei muito (8) para ambas as geleias.

Segundo Teixeira et al. (1987), para que determinado produto seja considerado aceito em termos de suas propriedades sensoriais, deve alcançar índice de aceitabilidade de, no mínimo, 70\%. De acordo com esse critério, percebe-se que as duas formulações alcançaram o índice de aceitabilidade, pois suas médias globais ficaram acima de 7 (gostei regularmente). Os provadores manifestaram maior preferência pela geleia light elaborada com pectina cítrica comercial (52\%). Um dos argumentos justificados na ficha sensorial foi que a geleia light, elaborada com pectina da casca de pequi, apresentou pontos pretos, dando aspecto inferior ao produto. Em relação à intenção de compra, houve uma divisão de opinião entre os provadores, sendo que $44 \%$ dos provadores comprariam as duas geleias, $26 \% \mathrm{com}$ prariam apenas a geleia light, elaborada com pectina comercial cítrica, $26 \%$ comprariam apenas a geleia light, elaborada com pectina da casca de pequi, e apenas 4\% não comprariam nenhuma das geleias.

TABELA 1 - Planejamento experimental, rendimento médio (\%) e transformado* e grau de esterificação da pectina (\%) extraída a partir da casca de pequi, em função do tempo (minutos), da temperatura $\left({ }^{\circ} \mathrm{C}\right)$ e da concentração de ácido cítrico $(\% \mathrm{~m} / \mathrm{v})$

\begin{tabular}{|c|c|c|c|c|c|c|c|c|c|}
\hline \multirow[b]{2}{*}{ Exp. } & \multicolumn{3}{|c|}{ Variáveis codificadas } & \multicolumn{3}{|c|}{ Variáveis originais } & \multirow{2}{*}{$\begin{array}{c}\text { Rend. } \\
\text { pectina }(\%)\end{array}$} & \multirow{2}{*}{$\begin{array}{l}\text { Rend. } \\
\text { Transf* }\end{array}$} & \multirow{2}{*}{$\begin{array}{c}\text { Grau de } \\
\text { Esterificação } \\
(\%)\end{array}$} \\
\hline & $\begin{array}{c}\text { Tempo } \\
\text { (minutos) }\end{array}$ & $\begin{array}{c}\text { Temp. } \\
\left({ }^{\circ} \mathrm{C}\right)\end{array}$ & $\begin{array}{c}\text { Ácido } \\
\text { Cítrico (\%) }\end{array}$ & $\begin{array}{l}\text { Tempo } \\
\text { (minutos) }\end{array}$ & $\begin{array}{l}\text { Temp. } \\
\left({ }^{\circ} \mathrm{C}\right)\end{array}$ & $\begin{array}{c}\text { Ácido. } \\
\text { Cítrico (\%) }\end{array}$ & & & \\
\hline 1 & -1 & -1 & -1 & 84 & 74 & 2 & 24,39 & 0,296 & 33,03 \\
\hline 2 & +1 & -1 & -1 & 156 & 74 & 2 & 20,82 & 0,271 & 25,34 \\
\hline 3 & -1 & +1 & -1 & 84 & 92 & 2 & 15,91 & 0,235 & 46,51 \\
\hline 4 & +1 & +1 & -1 & 156 & 92 & 2 & 15,70 & 0,233 & 48,07 \\
\hline 5 & -1 & -1 & +1 & 84 & 74 & 8 & 34,85 & 0,362 & 15,63 \\
\hline 6 & +1 & -1 & +1 & 156 & 74 & 8 & 55,86 & 0,484 & 13,78 \\
\hline 7 & -1 & +1 & +1 & 84 & 92 & 8 & 47,52 & 0,436 & 15,10 \\
\hline 8 & +1 & +1 & +1 & 156 & 92 & 8 & 20,53 & 0,269 & 12,85 \\
\hline 9 & $-1,68$ & 0 & 0 & 60 & 83 & 5 & 25,68 & 0,305 & 13,19 \\
\hline 10 & $+1,68$ & 0 & 0 & 180 & 83 & 5 & 31,37 & 0,341 & 11,79 \\
\hline 11 & 0 & $-1,68$ & 0 & 120 & 68 & 5 & 30,17 & 0,333 & 13,96 \\
\hline 12 & 0 & $+1,68$ & 0 & 120 & 98 & 5 & 19,71 & 0,264 & 13,16 \\
\hline 13 & 0 & 0 & $-1,68$ & 120 & 83 & 1 & 14,89 & 0,227 & 36,94 \\
\hline 14 & 0 & 0 & $+1,68$ & 120 & 83 & 9 & 41,47 & 0,401 & 11,84 \\
\hline 15 & 0 & 0 & 0 & 120 & 83 & 5 & 33,12 & 0,351 & 15,04 \\
\hline 16 & 0 & 0 & 0 & 120 & 83 & 5 & 35,02 & 0,363 & 16,48 \\
\hline 17 & 0 & 0 & 0 & 120 & 83 & 5 & 35,10 & 0,363 & 17,10 \\
\hline 18 & 0 & 0 & 0 & 120 & 83 & 5 & 33,20 & 0,352 & 17,13 \\
\hline 19 & 0 & 0 & 0 & 120 & 83 & 5 & 33,75 & 0,355 & 17,70 \\
\hline 20 & 0 & 0 & 0 & 120 & 83 & 5 & 33,99 & 0,357 & 16,99 \\
\hline
\end{tabular}

*Equação de transformação: $Z=\operatorname{arcsen} \sqrt{\frac{\text { Rend }}{100}} ;$ Exp.: experimento; t: tempo; T: temperatura de extração; AC: concentração de ácido cítrico; Rend.: rendimento da extração; Rend Transf.: rendimento transformado; GE: grau de esterificação. 
TABELA 2 - Análise de variância para rendimento transformado (a) e grau de esterificação (b) de pectina de casca de pequi, em função do tempo (minutos), da temperatura $\left({ }^{\circ} \mathrm{C}\right)$ e da concentração de ácido cítrico $(\% \mathrm{~m} / \mathrm{v})$

\begin{tabular}{lccccc}
\hline (a) Rend. Transf. & GL & SQ & QM & F & P \\
\hline (1) Tempo (L) & 0,000010 & 1 & 0,000010 & 0,00645 & 0,937553 \\
Tempo (Q) & 0,001156 & 1 & 0,001156 & 0,76708 & 0,401669 \\
(2) Temperatura (L) & $\mathbf{0 , 0 0 9 2 8 4}$ & $\mathbf{1}$ & $\mathbf{0 , 0 0 9 2 8 4}$ & $\mathbf{6 , 1 6 0 9 6}$ & $\mathbf{0 , 0 3 2 4 2 4}$ \\
Temperatura (Q) & 0,004476 & 1 & 0,004476 & 2,97003 & 0,115542 \\
(3) Concentração (L) & $\mathbf{0 , 0 4 7 8 8 5}$ & $\mathbf{1}$ & $\mathbf{0 , 0 4 7 8 8 5}$ & $\mathbf{3 1 , 7 7 6 7 8}$ & $\mathbf{0 , 0 0 0 2 1 6}$ \\
Concentração (Q) & 0,002124 & 1 & 0,002124 & 1,40938 & 0,262594 \\
1 L por 2 L & $\mathbf{0 , 0 0 8 8 4 4}$ & $\mathbf{1}$ & $\mathbf{0 , 0 0 8 8 4 4}$ & $\mathbf{5 , 8 6 9 2 7}$ & $\mathbf{0 , 0 3 5 8 9 8}$ \\
1 L por 3 L & 0,000041 & 1 & 0,000041 & 0,02688 & 0,873045 \\
2 L por 3 L & 0,000221 & 1 & 0,000221 & 0,14633 & 0,710077 \\
Resíduo & 0,015069 & 10 & 0,001507 & & \\
Total & 0,087986 & 19 & & & \\
(b) Grau de esterif. & $\mathrm{GL}$ & $\mathrm{SQ}$ & $\mathrm{QM}$ & $\mathrm{F}$ & $\mathrm{P}$ \\
\hline (1) Tempo (L) & 11,602 & 1 & 11,602 & 0,26385 & 0,618646 \\
Tempo (Q) & 3,579 & 1 & 3,579 & 0,08140 & 0,781235 \\
(2) Temperatura (L) & 81,689 & 1 & 81,689 & 1,85774 & 0,202787 \\
Temperatura (Q) & 11,081 & 1 & 11,081 & 0,25199 & 0,626542 \\
(3) Concentração (L) & $\mathbf{1 3 9 1 , 2 1 0}$ & $\mathbf{1}$ & $\mathbf{1 3 9 1 , 2 1 0}$ & $\mathbf{3 1 , 6 3 8 4 5}$ & $\mathbf{0 , 0 0 0 2 2 0}$ \\
Concentração (Q) & $\mathbf{3 1 9 , 4 1 9}$ & $\mathbf{1}$ & $\mathbf{3 1 9 , 4 1 9}$ & $\mathbf{7 , 2 6 4 1 2}$ & $\mathbf{0 , 0 2 2 4 9 8}$ \\
1 L por 2 L & 9,790 & 1 & 9,790 & 0,22265 & 0,647157 \\
1 L por 3 L & 0,515 & 1 & 0,515 & 0,01171 & 0,915951 \\
2 L por 3 L & 177,567 & 1 & 177,567 & 4,03817 & 0,072232 \\
Resíduo & 439,721 & 10 & 43,972 & & \\
Total & 2434,006 & 19 & & & \\
\hline & Coficis & & & &
\end{tabular}

* Coeficientes em negrito são significativos ( $\leq \leq 0,05)$.

TABELA 3 -Escores médios dos atributos sensoriais das geleias light elaboradas com pectina cítrica comercial e pectina extraída da casca de pequi

\begin{tabular}{lccc}
\hline Atributo & $\begin{array}{c}\text { Geleia } \text { light elaborada com } \\
\text { pectina cítrica comercial }\end{array}$ & $\begin{array}{c}\text { Geleia light elaborada com pectina } \\
\text { extraída da casca de pequi }\end{array}$ & $\mathrm{CV}^{1}$ \\
\hline Aparência $^{2}$ & $7,92 \mathrm{a} \pm 1,06$ & $7,32 \mathrm{~b} \pm 1,58$ & 18,27 \\
Textura & $7,70 \mathrm{a} \pm 1,41$ & $7,58 \mathrm{a} \pm 1,44$ & 17,70 \\
Sabor & $7,68 \mathrm{a} \pm 0,71$ & $7,72 \mathrm{a} \pm 1,51$ & 13,88 \\
Aroma & $7,52 \mathrm{a} \pm 0,71$ & $7,64 \mathrm{a} \pm 1,44$ & 18,53 \\
\hline
\end{tabular}

${ }^{1} \mathrm{CV}$ : Coeficiente de variação obtido na análise de variância.

${ }^{2}$ Letras iguais na mesma linha não diferem, a $5 \%$ de probabilidade de erro, pelo teste de Tukey. 
(a)

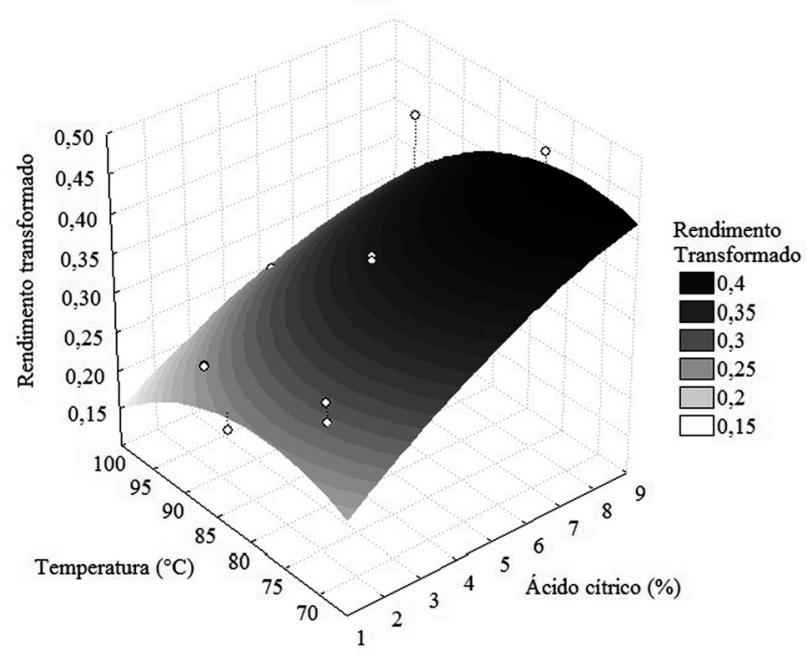

(b)

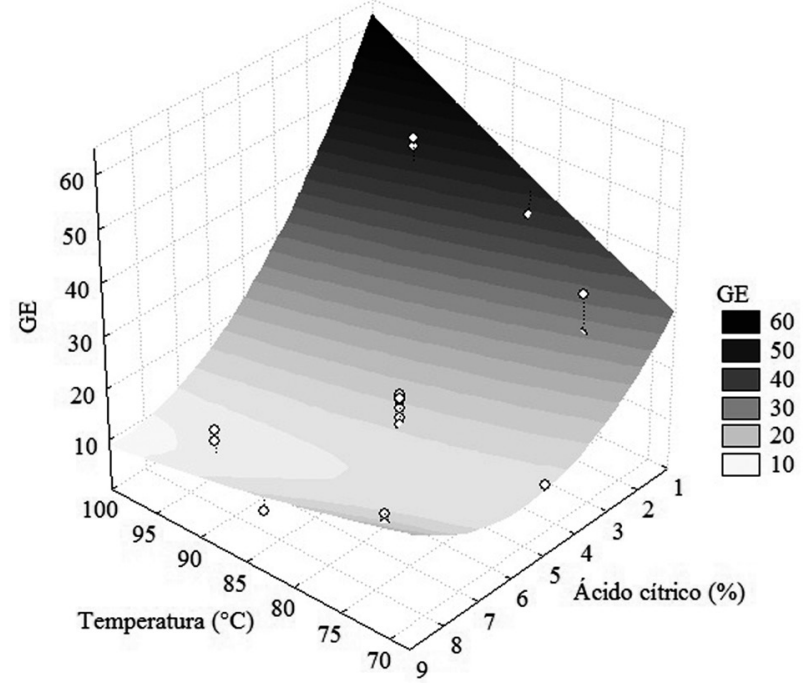

FIGURA 1- Curvas de superfície de resposta para os fatores de resposta rendimento transformado (a) e grau de esterificação (b) de pectina de casca de pequi, em função da temperatura $\left({ }^{\circ} \mathrm{C}\right)$ e concentração de ácido cítrico (\%) na extração 


\section{CONCLUSÕES}

A concentração de ácido cítrico, o tempo e a temperatura de extração afetam o rendimento do processo de extração da pectina obtida a partir de farinha de mesocarpo externo de pequi. Somente a concentração de ácido cítrico e a temperatura afetam o grau de esterificação das pectinas obtidas. As pectinas obtidas possuem baixo grau de esterificação. É viável, do ponto de vista tecnológico e sensorial, a aplicação de pectina de farinha de casca de pequi, obtida com concentração de ácido cítrico de $2 \%, 94$ minutos e $84^{\circ} \mathrm{C}$, em geleias light.

\section{REFERÊNCIAS}

CONSTENLA, D.; LOZANO, J. E. Kinetic model of pectin demethylation. Latin American Applied Research, Bahía Blanca, v. 33, p. 91-96, 2003.

FERTONANI, H. C. R. Estabelecimento de um modelo de extração ácida de pectina de bagaço de maçã. 2006. 82f. Dissertação (Mestrado em Ciência e Tecnologia de Alimentos) - Universidade Estadual de Ponta Grossa, Ponta Grossa, 2006.

HWANG, J. Purification and analysis of pectins. Journal of Korean Society of Food, Science and Nutrition, Seul, v. 22, n. 4, p. 500-509, 1993.

MARCON, M. V.; VRIESMANN, L. C.; WOSIACKI, G.; BELESKI-CARNEIRO, E. Pectins from apple pomace. Polímeros: Ciência e Tecnologia, São Carlos, v. 15, n. 2, p. 127-129, 2005.

MEILGARD, M.; CIVILLE, V.; CARR, B. T. Sensory evaluation techniques. Boca Raton: CRC Press, 1988. 279p.

MILOS, V.; NIKOLIC, A.; MOJOVIC, B. L. Hydrolysis of aplle pectin by the coordinated activity of pectin enzymes. Food Chemistry, London, v. 101, n. 1, p. 1-9, 2007.
MUNHOZ, C. L. Efeito das condições de extração sobre o rendimento e características da pectina obtida de diferentes frações de goiaba $c v$. Pedro Sato. 2008. 57f. Dissertação (Mestrado em Ciência e Tecnologia de Alimentos) - Escola de Agronomia e Engenharia de Alimentos, Universidade Federal de Goiás, Goiânia, 2008.

MUNHOZ, C. L.; SANJINEZ-ARGANDOÑA, E. J.; SOARES JÚNIOR, M. S. Extração de pectina de goiaba desidratada. Ciência e Tecnologia de Alimentos, Campinas, v. 30, p. 119-125, 2010.

NACHTIGALL, A. M.; ZAMBIAZI, R. C.; CARVALHO, D. S. Geleia light de hibisco: características físicas e químicas. Alimentos e Nutrição, Araraquara, v. 15, n. 2, p. 155-161, 2004.

PAGÁN, J.; IBARZ, A.; LLORCA, M.; PAGÁN, A.; BARBOSA-CÁNOVAS, G. V. Extraction and characterization of pectin from stored peach pomace. Food Research International, Barking, v. 34, n. 7, p. 605-612, 2001.

SOARES JÚNIOR, M. S.; BASSINELLO, P. Z.; CALIARI, M.; REIS, R. C.; LACERDA, D. B. C. L. ; KOAKUZU, S. N. Development and chemical characterization of flour obteined from mesocarpo of "pequizeiro" fruit. Ciência e Tecnologia de Alimentos, Campinas, v. 30, n. 4, p. 949-954, 2010.

SOARES JÚNIOR, M. S.; REIS. R. C.; BASSINELLO, P. Z.; LACERDA, D. B. C.; KOAKUZU, S. N.; CALIARI, M. Qualidade de biscoitos formulados com diferentes teores de farinha de casca de pequi. Pesquisa Agropecuária Tropical, Goiânia, v. 39, n. 2, p. 98-104, 2009.

TEIXEIRA, E.; MEINERT, E. M.; BARBETTA, P. A. Análise sensorial de alimentos. Florianópolis: UFSC, 1987. 180p.

VERA, R.; NAVES, R. V.; JORGE LUIZ DO NASCIMENTO, J. L. do; CHAVES, L. J.; LEANDRO, W. M.; SOUZA, E. R. B. Caracterização física de frutos do pequizeiro (Caryocar brasiliense Camb.) no Estado de Goiás. Pesquisa Agropecuária Tropical. Goiânia, v. 35, n. 2, p. 71-79, 2005. 